\title{
Public reporting: Will this help inform what patients and families need to know?
}

\author{
Susan D. Moffatt-Bruce, MD, PhD, MBA, FACS
}

\author{
From the Department of Surgery, The Ohio State University Medical Center, Columbus, Ohio. \\ Received for publication Aug 29, 2016; revisions received Jan 23, 2017; accepted for publication Feb 6, 2017 \\ available ahead of print March 11, 2017. \\ Address for reprints: Susan D. Moffatt-Bruce, MD, PhD, MBA, FACS, Department of Surgery, The Ohio State \\ University Medical Center, 130 Doan Hall, 410 West 10th Ave, Columbus, OH 43210 (E-mail: Susan. \\ moffatt-bruce@osumc.edu). \\ J Thorac Cardiovasc Surg 2017;153:1623-6 \\ $0022-5223 / \$ 36.00$ \\ Copyright (C) 2017 by The American Association for Thoracic Surgery \\ http://dx.doi.org/10.1016/j.jtcvs.2017.02.017
}

Health care is in the midst of tremendous change, and as with any change, tensions mount. The interplay of payment reform, consumer-driven models, disruptive innovation, and "big data" have placed increased pressure on the American health care system and its providers. The perpetual development and provision of new care models, and consolidation of health systems and physician practices, has led to changes in provider strategy and leadership models and resultant expectations across the entire care paradigm. Central to this change has been the role of transparency; not only among providers and payers but also for the patients we serve.

There have been many steps along this road from translucency to the current transparency expectations. To Err Is Human, ${ }^{1}$ published by the Institute of Medicine more than a decade ago, was the launch of the modern safety movement as we know it, which then evolved into the "accountability" epidemic, as described by Wachter and Pronovost, ${ }^{2}$ which was followed by the Lucian Leape " no blame" paradigm. ${ }^{3}$ As a sort of counterbalancing argument, Peter Pronovost's "blame versus accountability" clarification was put forward, which was finally rounded out by Mr Boothman's innovative and thought-provoking work on medical error disclosure. ${ }^{4-6}$ These pioneers and resultant expectations have taken more than a decade to truly engrain in providers the realistic expectations our patients and their families may have. Some might say there have been baby steps and we have only served to set the platform for what is about to come as our patients become more educated and consumerism drives many markets.

As a result of the transparency paradigm and constant attention on health care from so many different stakeholders, attempts to assess the quality and safety of hospitals and providers have proliferated at an astounding rate. Transparency efforts have become a cottage industry and include a growing number of consumer-directed hospital rating systems. However, relatively little is known about what these rating systems reveal other than to confirm that there appear to be more than 700 "Top-100" hospitals

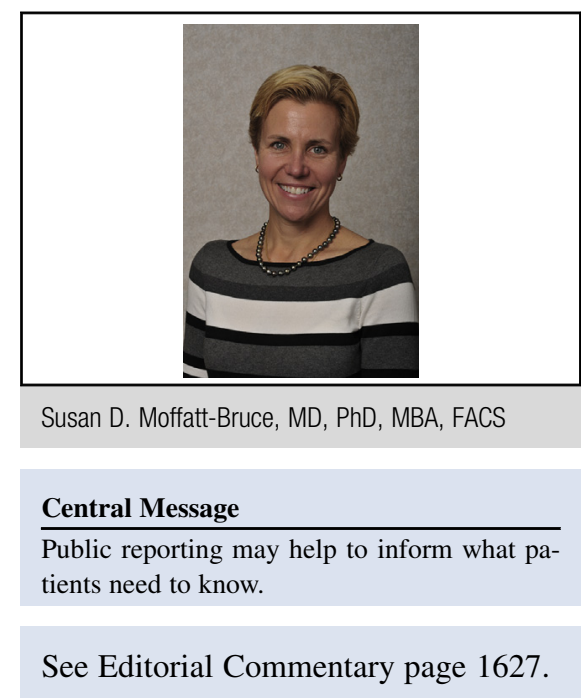

in America. To better understand differences in hospital ratings, Pronovost co-authored a published comparison of national rating systems, including U.S. News \& World Report's "Best Hospitals" Report, Leapfrog, Centers for Medicare and Medicaid Services' Hospital Compare, Consumer Reports, and Healthgrades. ${ }^{7}$ Dr Pronovost designated "high" and "low" performers for each rating system and examined the overlap among rating systems and how hospital characteristics corresponded with performance for each. No American hospital was rated as a high performer by all 4 national rating systems, and only $10 \%$ of the 844 hospitals rated as a high performer by one rating system were rated as a high performer by any of the other rating systems. There was a general lack of agreement among the national hospital rating systems, a finding attributed to the fact that each system uses its own rating methods, has a different focus to its ratings, and stresses different measures of performance. Furthermore, this influential research group found that differences across hospital ratings add complexity to evaluating a hospital's actual quality. These rating systems do make it difficult for payers to accurately recognize and reward hospitals for high-quality care. This difficulty has the potential to render decision making for hospital leadership very confusing with regard to areas of focus for quality improvement. Last, and perhaps most important, the authors who represent some of the most elite in health care quality and patient safety concluded that the rating systems, as they currently exist, confuse current and prospective patients and families rather than provide clarity. ${ }^{7}$ What is really needed for our patients, health care institutions, and 
providers is an accurate rating of the rating systems that currently exist. All are not equal.

The challenge for hospitals to be transparent in sharing their quality and outcomes data has now been passed on to surgeons. There is a reality for surgeons providing care to patients with highly complex diseases in an evidence-based fashion that minimally risk-adjusted data may not reflect that level of complexity yet be used publically. Much controversy has stemmed from the release of several of these types of data, including the ProPublica Surgeon Scorecard, and the Consumers' Checkbook. ProPublica analyzed the complication rates of 16,827 surgeons operating in 3575 hospitals. The report used Medicare data from 2009 to 2013 for 8 common procedures that were felt to be elective and low risk. Admissions through the emergency room and transfers from other facilities were excluded from the report. Two measures of harm were used: in-hospital mortality and readmissions within 30 days with a primary diagnosis identified as a likely complication. A risk adjustment model was used; however, the model seems unclear, not widely available in existing reports, and more recently criticized. ${ }^{8,9}$ The data attempt to reflect how a surgeon would perform at an averageperforming hospital on an average patient population rather than the more complex patient population often treated at large academic institutions.

Another surgeon performance reporting agency, Consumers' Checkbook, analyzed Medicare data from 2009 to 2012 for 14 groups of commonly performed procedures. Transfers from other hospitals were excluded from this report. Each surgeon with a sufficient population received a star ranking based on performance in mortality within 90 days of the admission, prolonged hospital stay, and 90-day readmissions. An observed and predicted rate is calculated for each surgeon. The number of stars from 3 to 5 reflects how significantly higher the observed rate is compared with the predicted rate. Not unexpectedly, the release of these "score cards" triggered much discussion on the topic of performance data as true and valid indicators of quality. Suffice it to say, if the patients were not confused relative to rating systems that reflect hospital performance, how are they going to deal with practitioner-level data? Although intentions may be positive, and one must assume they are, care must be taken to ensure that reported data are clinically validated, reported accurately, and have the buyin of key stakeholders, including the physicians, patients, and their family members.

Public reporting of hospital and surgeon-specific outcomes may be the newest, overt challenge to surgeons. Transparency of surgeon outcomes starts at the bedside, whereby patients have a right to transparency in the form of disclosure. The surgeon's professional obligation is within the American Medical Association's Code of Medical Ethics, which speaks to "situations occasionally occur in which a patient experiences significant medical complications that may have resulted from the physician's mistake or judgment. In these situations, the physician is ethically required to inform the patient of all the facts necessary to ensure understanding of what has occurred." 10,11 Concerning the patient's right to informed care, patients are entitled to honest and transparent information. A patient's right to informed consent is an active process and an understanding of the potential success and complications of the operation, and the true past performance of the surgeon to establish accountability for both the surgeon and the patient. This is the start of the transparency conversation. Transparency, at all levels of the health care continuum, is defined as the free, uninhibited sharing of information, and has been touted as the single attribute of a culture of safety. ${ }^{12}$ Lack of transparency restricts critical information for individual patients and systems, and impairs the quality of health care overall.

Physician attitudes to reporting performance, good or bad, have been studied and even criticized. ${ }^{13-16}$ Following the To Err Is Human publication, England, Australia, New Zealand, and Canada also identified adverse events and errors as a major health problem. ${ }^{14-16}$ Studies from these countries revealed that as few as $30 \%$ of errors have been disclosed to patients. ${ }^{16}$ The United States has been compared with Canada, in particular, because although being neighboring countries, the respective malpractice environments to date have been fairly disparate. ${ }^{15}$ In a survey of more than 2600 physicians in the 2 countries, $64 \%$ agreed that patient safety errors were a serious problem; however, $50 \%$ disagreed that errors were usually a result of a system failure. Interestingly, $98 \%$ endorsed disclosing serious errors to patients but only $58 \%$ have actually completed this process.

Although there was tremendous variation in the degrees of transparency, there were predictors of attitudes supporting transparent communication among practitioners. Of particular interest, young, female, American (vs Canadian) physicians in academic institutions who had undergone previous disclosure training were must more apt to openly disclose errors with their patients. ${ }^{14,15}$ One can only surmise that in our current environment of untethered transparency initiatives at the hospital and practitioner levels, this may be the same phenotype of provider that could not only help to inform our transparency paradigm, but may also embrace it in a productive and informative manner.

The Society of Thoracic Surgeons (STS) supports the public's right to know the quality of surgical outcomes and considers public reporting an ethical responsibility of the specialty. STS Public Reporting Online enables STS Adult Cardiac and Congenital Heart Surgery Database participants to voluntarily report to each other and to the public their heart surgery scores and star ratings. This is completely voluntary at this point, and in the realm of adult cardiac surgery includes coronary artery bypass grafting 
(CABG), aortic valve replacement (AVR), and combined CABG/AVR cases to date and is only at the hospital or group level. ${ }^{17}$

Further embracing public reporting, the STS Quality Measurement Task Force is developing a portfolio of composite performance measures for the most commonly performed procedures in adult cardiac surgery and thoracic surgery. ${ }^{18,19}$ Although these composite measures are new, the STS Adult Cardiac Surgery Database (ACSD) was actually initiated in 1989 and includes more than 1085 participating centers, representing $90 \%$ to $95 \%$ of current US-based adult cardiac surgery hospitals. Since its inception, the primary goal of the STS ACSD has been to use clinical data to track and improve cardiac surgical outcomes. ${ }^{17}$

The STS public reporting program, a program that initially proved anxiety-provoking for surgeons, was evaluated after 4 years of implementation. ${ }^{17}$ Among 8929 unique observations, 916 sites $(10.3 \%)$ were classified as low performing, $6801(76.2 \%)$ were average, and 1212 $(13.6 \%)$ were high performing. STS public reporting participation varied from $22.2 \%$ to $46.3 \%$ over the 9 reporting periods. Risk-adjusted, patient-level mortality rates for isolated CABG were consistently lower in public reporting versus nonreporting sites $(P$ value range: $<.001$ to .0077). Interestingly, STS programs that voluntarily participate in public reporting have significantly higher volumes and performance, and no evidence of risk aversion was found. ${ }^{17}$ This finding alone speaks to the reality that the public wants to know how we as surgeons perform. The STS public reporting program, with clinically relevant and validated data, can help to inform patients of meaningful outcomes.

So how do we go about sharing our practice and our failings publically? Gallagher et $\mathrm{al}^{12}$ speak of the adage that applies to individual practitioners as well as public reporting in general: "Explore, do not ignore." Get the facts, engage the family when they choose, discuss before disclosure, have a plan, and continue to communicate. As we become more and more transparent relative to performance, whether it is correct or not, there will be questions, and we need to, as surgeons, be prepared to answer them. And there are benefits. Communicating openly and honestly about all realms of outcomes data that range from full disclosure about errors to system-based outcomes, will improve surgeonpatient relationships, patient and family satisfaction, and surgeon well-being, and will decrease litigation and malpractice costs and ultimately support "Just Culture" and accountability. ${ }^{5,12}$

As surgeons, we must commit to change so that our patients and families have a clear understanding of our performance, good or bad. Commitment to change will require early, informed, and continuous conversation with patients, institutional transparency, and support and discussion algorithms for surgeons. Clarity of data and performance will help to build consistency and build trust and engagement; ultimately this transparency will be perceived, I believe, as caring.

In the past decade, much emphasis has been placed on the quality of medical care and great efforts have been put forward to identify patient safety improvement opportunities. As consumerism has grown, public rating systems and marketing strategies have exploded throughout all domains of health care. It has now become a complicated process to manage and actually use these quality and patient safety programs and subsequent ratings to actually facilitate better care and meet the expectations of patients, board members, and academic peers. It is imperative that we as surgeons use the vast amount of data generated, validate it, and use it to effect change. Surgeons need to be at the table in the journey toward transparency so that the data generated are accurate, validated, and patient-centric. Ultimately, public reporting may be just the ticket to help inform what patients and families need to know.

\section{Conflict of Interest Statement}

Author has nothing to disclose with regard to commercial support.

\section{References}

1. Kohn KT, Corrigan JM, Donaldson MS. To Err Is Human: Building a Safer Health System. Washington, DC: National Academies Press; 1999.

2. Wachter RM, Pronovost PJ. Balancing "no blame" with accountability in patient safety. N Engl J Med. 2009;361:1401-5

3. Leape LL. Who's to blame. Jt Comm J Qual Patient Saf. 2010;36:150-1.

4. Wu A, Pronovost P. Telling patients the truth. Health Aff (Millwood). 2003;22: 249; author reply 249 .

5. Hickson GB, Federspiel CF, Pichert JW, Miller CS, Gauld-Jaeger J, Bost P. Patient complaints and malpractice risk. JAMA. 2002;287:2951-7.

6. Boothman RC, Imhoff SJ, Campbell DA Jr. Nurturing a culture of patient safety and achieving lower malpractice risk through disclosure: lessons learned and future directions. Front Health Serv Manage. 2012;28:13-28.

7. Austin JM, Jha AK, Romano PS, Singer SJ, Vogus TJ, Wachter RM, et al. National hospital ratings systems share few common scores and may generate confusion instead of clarity. Health Aff (Millwood). 2015;34:423-30.

8. Friedberg MW, Pronovost PJ, Shahian DM, Safran DG, Bilimoria KY, Elliott MN, et al. A Methodological Critique of the ProPublica Surgeon Scorecard. Santa Monica, Calif: RAND Corporation; 2015. Available at: http:/ www.rand.org/pubs/perspectives/PE170.html. Accessed December 7, 2016

9. Ban KA, Cohen ME, Ko CY, Friedberg MW, Stulberg JJ, Zhou L, et al. Evaluation of the ProPublica Surgeon Scorecard "adjusted complication rate" measure specification. Ann Surg. 2016;264:566-74.

10. AMA Council on Ethical and Judicial Affairs. Opinion 8. Code of Medical Ethics: Opinions on Physicians \& the Health of the Community. Chicago, Ill: American Medical Association; 2016.

11. American College of Physicians. American College of Physicians Ethics Manual. Fourth edition. Ann Intern Med. 1998;128:576-94.

12. Gallagher TH, Mello MM, Levinson W, Wynia MK, Sachdeva AK, Snyder Sulmasy L, et al. Talking with patients about other clinicians' errors. $N$ Engl J Med. 2013;369:1752-7.

13. Blendon R, DesRoches C, Brodie M, Rosen A, Benson JM, Schneider E, et al View of practicing physicians and the public on medical errors. N Engl J Med. 2002;347:1933-40.

14. Baker GR, Norton PG, Flintoft V, Blais R, Brown A, Cox J, et al. The Canadian Adverse Events Study: The incidence of adverse events among hospital patients in Canada. CMAJ. 2004;170:1678-86. 
15. Hussey PS, Anderson GF, Osborn R, Feek C, McLaughlin V, Millar J, et al. How does the quality of care compare in five countries. Health Aff (Millwood). 2004;23:89-99.

16. Schoen C, Osborn R, Huynh PT, Doty M, Zapert K, Peugh J, et al. Taking the pulse of health care systems: experiences of patients with health problems in six countries. Health Aff (Millwood). 2005. Suppl Web Exclusives:W5-509-25.

17. Shahian DM, Grover FL, Prager RL, Edwards FH, Filardo G, O'Brien SM, et al. The Society of Thoracic Surgeons voluntary public reporting initiative: the first 4 years. Ann Surg. 2015;262:526-35.
18. Badhwar V, Rankin JS, He X, Jacobs JP, Gammie JS, Furnary AP, et al. The Society of Thoracic Surgeons mitral repair/replacement composite score: a report of the Society of Thoracic Surgeons Quality Measurement Task Force. Ann Thorac Surg. 2016;101:2265-71.

19. Kozower BD, O’Brien SM, Kosinski AS, Magee MJ, Dokholyan R, Jacobs JP, et al. The Society of Thoracic Surgeons Composite Score for rating program performance for lobectomy for lung cancer. Ann Thorac Surg. 2016;101:1379-86. 